\title{
Inhaltsverzeichnis/Contents
}

F. N. Rhines

R. Riedl,

H. Kerber,

Y.-K. Jang

E. Horn,

U. Lotter
Microstructology

Mikrostruktologie

Metallographische Darstellung des Primärgefüges und nichtmetallischer Phasen von gerichtet erstarrten Stählen

Metallographic Characterization of the Primary Structure and Non-metallic Phases of Directionally Solidified Steels

Bestimmung der Kornorientierung an Oberflächen von Elektroblechen mit Hilfe von Ätzgrübchen. Teil 1: Systematik zur Interpretation der REM-Abbildungen von Ätzgrübchen zur genauen Orientierungsbestimmung und Vorstellung einer Makroätzung zur einfachen Abschätzung der Orientierung

Determining the Grain Orientation on the Surface of Electrical Sheets by Means of Etch Pits. Part 1: Systematic Approach to Interpret SEM Micrographs of Etch Pits for Accurate Orientation Determination and Introduction of a Macroetching Technique for the Simple Estimation of the Orientation

A "Sample Friendly" Metallographic Gold Etch

Ein ,,probenfreundliches" metallographisches Goldätzmittel

407

Failure of Cadmium Plated EN24 Steel Thread Inserts

Schäden an kadmiumplattierten Gewindeeinsätzen aus Stahl EN24

Tagungskalender/Meeting Diary 


\section{von Zeiss}
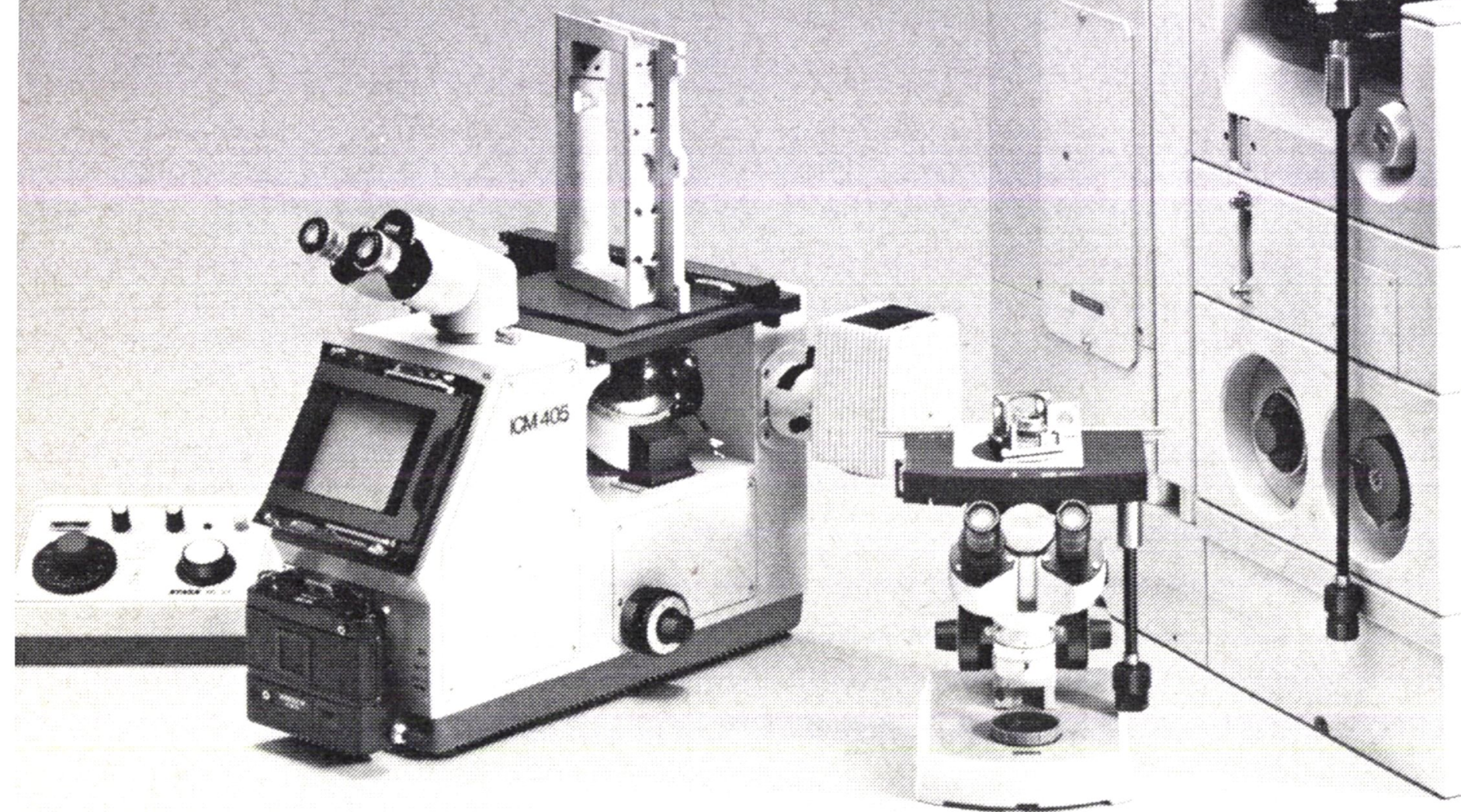

Die inversen Metallmikroskope von Zeiss zeichnen sich aus durch

- hohe Stabilität

- problemloses Untersuchen großer Proben

- kontrastreiche, farbgetreue Wiedergabe bis zum Sehfeldrand

- einfache und bequeme Bedienung: die SchliffFläche der Probe auf dem Objekttisch befindet sich plan in der Schärfeebene.

\section{Zeiss - Spitzenleistung in Optik, Feinmechanik und Elektronik}

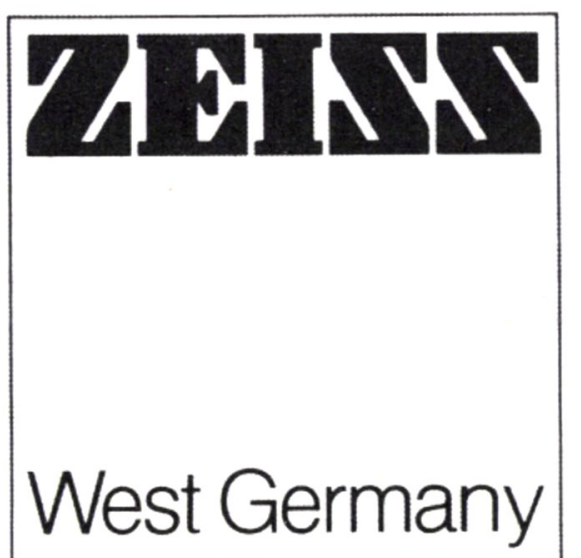

Carl Zeiss

Abteilung Mikroskope

Postach 1369/1380

D-7082 Oberkochen
Zeiss bietet Ihnen die passende Ausrüstung - ob für Routine- oder Forschungsarbeiten:

Invertoskop M,

das kleine bedienungsfreundliche Mikroskop für Routineuntersuchungen im Hellfeld, polarisierten Licht und Differential-InterferenzKontrast (DIC).

IM 35,

das kompakte Mikroskop hoher Stabilität für alle Arbeiten der inversen Auflichtmikroskopie. Adaptionsmöglichkeit für handelsübliche Kleinbild SLR-Kamera, Fernsehoder Cinekamera und Geräte zur quantitativen Bildanalyse.

ICM 405,

das vielseitige und bewährte Kameramikroskop für alle inversen Auflichtuntersuchungen. Integrierte Kamera für Groß- und Kleinformat. Anschluß für Fernsehoder Cinekamera sowie Geräte zur quantitativen Bildanalyse.
Axiomat $I A C$,

das inverse Kameramikroskop, das durch die module Bauweise sowohl optisch als auch durch Zusatzeinrichtungen einen vielseitigen Ausbau ermöglicht. Höchste mechanische und thermische Stabilität.

Eingebaute vollautomatisch belichtende Groß- und Kleinbildkamera. Spitzenleistung der Optik.

\section{Info-Coupon}

Ich bitte um mehr Informationen über das inverse Metallmikroskop-Programm von Zeiss.

Absender: 